\title{
Implementando as novas diretrizes curriculares para a educação médica: o que nos ensina o caso de Harvard?
}

\author{
Implementing the new curricular guidelines for medical \\ education: what does the Harvard case teach us?
}

Adriana Cavalcanti de Aguiar ${ }^{1}$

\section{O atual momento da educação médica no Brasil}

Podemos situar o atual movimento de transformação da educação médica no contexto da redemocratização brasileira, por promover avanços na garantia do direito constitucional à saúde, por meio de mudanças nas relações sociais implicadas na educação e prática médicas. O próprio processo de definição de diretrizes curriculares foi um exercício de democracia. A insatisfação de usuários do sistema de saúde expressa pelos movimentos sociais encontrou eco nas lideranças acadêmicas, organizadas em torno da Associação Brasileira de Educação Médica (ABEM), da Comissão Interistitucional Nacional de Avaliação da Educação Médica (CINAEM), e da Rede UNIIDA. Sucessivos fóruns de discussão congregaram alunos, docentes e gestores, acumulando credibilidade e adquirindo legitimidade perante a sociedade e o governo federal. Isto levou o Ministério da Educação a recentemente assumir o compromisso de encaminhar ao Conselho Nacional de Educação diretrizes curriculares para a educação médica consensuais na comunidade acadêmica da área, e que colocam em pauta o estabelecimento de um novo pacto entre escolas médicas e sociedade.

As novas diretrizes avançam na superação do chamado modelo Flexneriano, em que a base científica foi descolada da prática médica, promovendo a fragmentação do conhecimento, com negligência de aspectos psicossociais e culturais que permeiam o exercício da Medicina. Além disso, a educação médica tradicional, centrada no professor, deixa a desejar na preparação de profissionais críticos e aptos a lidar com mudanças rápidas e constantes na base de conhecimento.

${ }^{1}$ Coordenadora Acadêmica do Curso de Medicina da Universidade Estácio de Sá. Consultora do Instituto de Medicina Social da Universidade do Estado do Rio do Rio de Janeiro. Membro do Grupo Coordenador da Rede de Apoio à Educação Médica (RAEM), da Associação Brasileira de Educação Médica. <adrianaaguiar@openlink.com.br> 
Na nova proposta, as competências a serem demonstradas pelos egressos incluem "dominar os conhecimentos científicos básicos de natureza biopsicossocioambiental subjacentes à prática médica", necessários para um exercício profissional não-autoritário, capaz de negociar condutas $e$ intervenções a partir da escuta atenta das perspectivas de pacientes, famílias e comunidades. Os profissionais que nossas escolas médicas estarão formando deverão estar aptos a "atuar na proteção e na promoção da saúde e na prevenção de doenças, bem como no tratamento e na reabilitação dos problemas de saúde", adotando uma perspectiva integral. Para tal, os conteúdos propugnados incluem os "determinantes sociais, culturais, comportamentais, psicológicos, ecológicos, éticos e legais, nos níveis individual e coletivo, do processo saúde-doença", sendo o "eixo do desenvolvimento curricular ... baseado nas necessidades de saúde dos indivíduos e das populações, referidas pelo usuário e identificadas pelo setor saúde".

Quanto aos processos de ensino-aprendizagem, as novas diretrizes fomentam "a participação ativa do aluno na construção do conhecimento e a integração entre os conteúdos, além de estimular a interação entre o ensino, a pesquisa e a extensão", contribuindo para reconstruir conexões entre conhecimentos provenientes das ciências básicas, clínicas e humanas, $e$ fortalecendo uma postura ativa e crítica de nossos futuros médicos, a partir da ênfase no aprendizado baseado na prática, e em vários "cenários", não apenas o hospital universitário, "permitindo ao aluno conhecer ativamente situações variadas de viver a vida, organizar cuidados à saúde e trabalhar em equipe multiprofissional" além de "buscar a educação permanente, especialmente a auto-aprendizagem".

Com a formulação dessas diretrizes e a partir do compromisso governamental de honrá-las, cabe-nos agora a tarefa da implementação, respeitando as singularidades de nossas escolas, e utilizando da melhor forma os recursos que já existem. Parte significativa deste desafio é a ampliação do apoio dos docentes e gestores nas academias médicas. Sabemos que as resistências são expressivas. Para muitos é difícil abrir-se para o novo. Outros estão contentes repetindo o que seus próprios mestres faziam. Há os que manifestam insatisfação, mas não confiam na possibilidade de mudar o contexto institucional em que trabalham. Para lidarmos com as dúvidas de nossos colegas docentes e com nossos próprios questionamentos, proponho que examinemos um caso de inovação curricular que completou quinze anos.

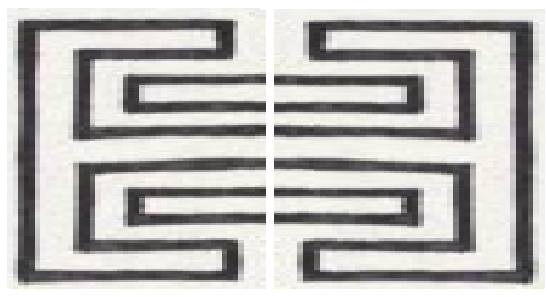




\section{Refletindo sobre o caso de Harvard}

Embora o movimento de transformação da educação médica no Brasil seja consonante com iniciativas análogas efetuadas em outros contextos nacionais, na maioria dos países ocidentais a excelência acadêmica se mede pela capacidade de pesquisar e, principalmente, de publicar artigos em boas revistas especializadas. É provável que nossas melhores instituições estejam certas da importância da pesquisa, e menos convencidas da necessidade de aprimorar o ensino. Um caso interessante é o da Universidade Harvard, instituição de excelência em pesquisa, que conseguiu avançar no aprimoramento do ensino médico.

Ao longo de meu programa de doutorado, quando estudei as conseqüências das mudanças curriculares implementadas na Escola de Medicina de Harvard (HMS) para os docentes, uma pergunta se colocou desde o início: por que motivos a HMS, que já ofereceu ao mundo 15 agraciados com o Prêmio Nobel, que é disputada num processo de seleção rigorosíssimo, e onde os alunos admitidos pagam uma fortuna para se formarem, haveria de se preocupar em mudar?

A mudança curricular da HMS ocorreu no contexto de ampliação dos questionamentos sobre os rumos da prática e da educação médica americanas, fomentados pelos movimentos sociais e sistematizados pela Association of American Medical Colleges (AAMC). No documento intitulado "Médicos para o Século XXI" (1984) a AAMC enfatizava pontos que também orientam nossas novas diretrizes: a aquisição de atitudes $e$ habilidades adequadas à prática profissional é tão importante quanto a aquisição de conhecimento; os estudantes devem ser preparados para a promoção da saúde e prevenção da doença, junto a indivíduos e comunidades; a escola deve preparar seus alunos para a educação permanente, o que inclui a habilidade de identificar, formular e resolver problemas e avaliar informação nova de forma crítica; o processo ensino-aprendizagem deve centrar-se no estudante, com menos ênfase na memorização; o foco da aprendizagem deve ser as necessidades dos pacientes e suas famílias, com o docente exercendo papel de mentor. Um ponto importante do documento da AAMC ao qual voltarei posteriormente é a conclusão que "a motivação dos docentes de devotar significativo tempo e energia para um programa integrado de educação médica dependerá de um explícito reconhecimento institucional da importância desta missão institucional fundamental” (p. 24). Em outras palavras, o processo de transformação da educação médica, por demandar entusiasmo e tempo dos professores, demanda também mecanismos de incentivo à carreira docente que promovam a excelência no ensino a um patamar compatível com o alcançado pela excelência na pesquisa.

Ainda no fim dos anos setenta, sob a coordenação do diretor Daniel Tosteson, o diagnóstico da situação elaborado

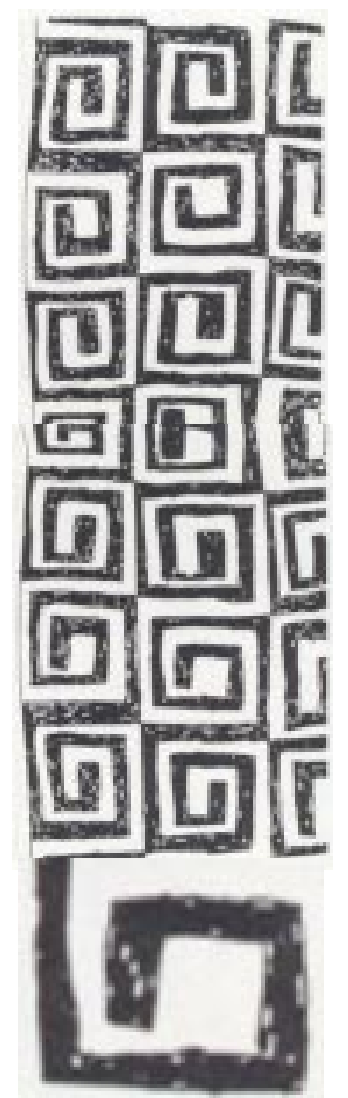


pela comunidade acadêmica da HMS apontava para um quadro bastante semelhante ao que atualmente presenciamos em muitas escolas brasileiras: uma massa de estudantes "anônimos" sendo "assoberbada" por informações "fragmentadas" transmitidas em aulas expositivas e de qualidade "variável", num processo que valorizava mais a memorização do que o raciocínio crítico (Aldestein E Ramos 1994).

Com este diagnóstico, em 1985 a HMS implementou um currículo inovador, inicialmente como projeto-piloto, sendo estendido para toda a escola dois anos depois. Conhecido como "New Pathway to Medical Education", o novo currículo tinha como estratégias a Aprendizagem Baseada em Problemas (ABP), o processo ensino-aprendizagem centrado no estudante e o resgate da relação médico-paciente como elemento agregador de conteúdos biopsicossociais.

Embora outras escolas americanas, canadenses e européias já houvessem adotado inovações até mais radicais, a adoção do novo modelo na HMS marcou a incorporação de um novo modelo no cerne das instituições de ensino e pesquisa de indiscutível prestígio, gerando uma significativa pressão para mudanças em outras instituições.

Segundo Armstrong (1991), os "três objetivos pedagógicos" que nortearam a mudança foram: "conhecimento, habilidades e sensibilidade ..., [entendida como] uma consciência ética e abertura para o mundo do paciente" (p. 138). A criação de canais de comunicação e persuasão junto ao corpo docente foi enfatizada, mas mesmo assim "considerável resistência, ceticismo, e mesmo hostilidade explícita emergiram” (Moore 1991, p.81). Docentes manifestavam preocupação com o "caráter aparentemente assistemático das inovações" e com a "falta de reconhecimento acadêmico" por seus esforços (p.81).

Durante a elaboração de minha tese de doutorado (Aguiar, 2000) pude interagir com docentes e gestores da HMS, discutindo a experiência dos tutores na seqüência de cursos sobre a relação médico-paciente, que alia o ensino das habilidades necessárias à prática, com a reflexão sobre as forças culturais, sociais, econômicas e psicológicas que afetam o cuidado aos pacientes (PDI Course Guide). Pude apreender que, atualmente, a maioria dos tutores que entrevistei aprecia o trabalho, embora a função docente seja hoje mais complexa que no passado. Eles reportam gratificar-se com a interação mais próxima com os alunos, quando observam seu rápido desenvolvimento profissional e pessoal. O curso estabeleceu um expressivo grau de sofisticação quanto ao ensino das habilidades $e$ atitudes, que são hoje objeto de avaliações rigorosas, devendo os alunos demonstrar maestria na relação com pacientes, colegas e situações-problema.

Percebe-se hoje um equilíbrio dinâmico entre forças que enfatizam a base biomédica e os humanistas, possível em função da seriedade e consistência do trabalho destes últimos e ao seu investimento em capacitação docente. Um fator para a "diminuição das tensões junto aos docentes" foi a criação, em 1989, da "teacher-clinician track", uma nova vertente da carreira acadêmica que gratifica liderança e excelência no ensino, consideradas como critério para o avanço na carreira e para a estabilidade docente (Lovejoy $\&$ Clark, 1995). 


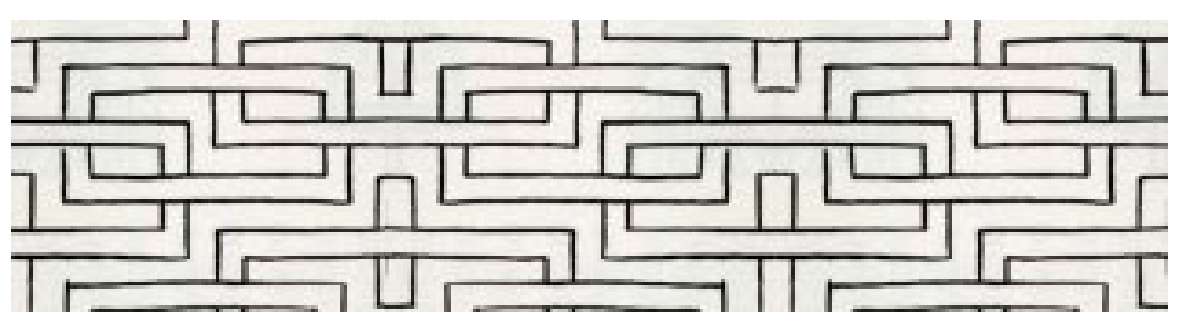

\section{Conclusão}

Com as novas diretrizes vigorando, em futuro próximo esperamos avançar num processo de redemocratização interno ao aparelho formador de médicos, com renegociação de autoridade entre professores e alunos, médicos e pacientes, mediando novas relações a serem estabelecidas entre serviços de saúde e usuários, e dentro das equipes de saúde. Neste novo contexto teremos profissionais preparados para lidar com diferenças culturais, sociais, de gênero, de etnia, de valores e representações sobre saúde e doença, favorecendo a criação de estratégias efetivas para alcançarmos a integralidade do cuidado e a eqüidade do direito à saúde.

Poderemos, assim, caminhar na superação do modelo biomédico, com a incorporação de seus benefícios no âmago de um novo modelo que incorpore também os conhecimentos psicossociais, de forma a garantir legitimidade e qualidade para as escolas e para a profissão médica, de forma análoga ao que vem fazendo a HMS.

A observação de instituições com mais acúmulo no sentido da mudança pode conferir maior segurança e inspirar persistência para os agentes de mudança no Brasil. Trata-se de trabalharmos no fortalecimento de nossa própria capacidade, como alunos, docentes e gestores, de auto-crítica $e$ busca de aperfeiçoamento permanentes, de forma análoga ao que esperamos de nossos estudantes. Se aliarmos a isto mecanismos institucionais de promoção docente para os que se dedicarem ao estudo $e$ pesquisa dos processos ensino-aprendizagem, será possível vislumbramos uma vida profissional mais criativa e gratificante para docentes, gestores $e$ futuros profissionais.

\section{Referências bibliográficas}

AGUIAR. A. C. Consequences for Faculty of Changes in Medical Education: the experience of tutoring a course about the patient-doctor relationship. Cambridge (MA), 2000. Tese (Doutorado em Educação). Harvard Graduate School of Education.

ALDESTEIN, J., RAMOS, M. Searching. In: TOSTESON, D., ALDESTEIN, J., CARVER, S. (Editors)

New Pathways to Medical Education: learning to learn at Harvard Medical School. Cambridge (MA): Harvard University Press, 1994. p.14-29.

ARMSTRONG, E. A hybrid model of problem-based learning. In: BOUD, D, FELLETI, G. (Editors) The

challenge of Problem-Based Learning. New York: St. Martin's Press, 1991. p. 137-49. ASSOCIAÇÃO BRASILEIRA DE EDUCAÇÃO MÉDICA. Proposta de minuta do anteprojeto das 
diretrizes curriculares nacionais para os cursos de graduação em Medicina. Brasília, 2000. ASSOCIATION OF AMERICAN MEDICAL COLLEGES. Physicians for the twenty-first century: the GPEP Report. Washington (DC), 1984.

HARVARD MEDICAL SCHOOL. Course Catalog. Boston (MA), 1998-9.

HARVARD MEDICAL SCHOOL. Patient-doctor relationship year I. Course guide. Boston (MA),

1997-8.

LOVEJOY, F., CLARK, M. A promotion ladder for teachers at Harvard Medical School: experience and challenges. Acad. Med., v.70, p.1079-86, 1995.

MOORE, G. Initiating problem-based learning at Harvard Medical School. In: BOUD, D., FELLETI, G.

(Editors) The challenge of Problem-Based Learning. New York: St. Martin's Press, 1991. p.80-7.

PALAVRAS-CHAVE: Educação médica; currículo; diretrizes.

KEY WORDS: medical education; curriculum; guidelines.

PALABRAS CLAVE: educación medica; curriculum; pautas.

Recebido para publicação em:30/10/00. Aprovado para publicação em: 28/11/00.

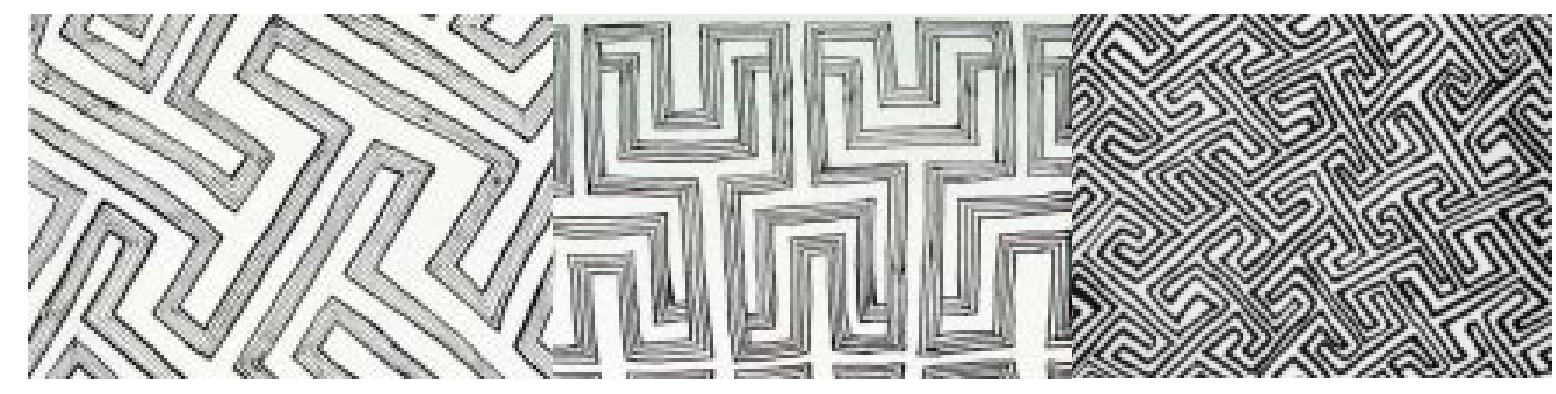

166 Interface - Comunic, Saúde, Educ 8 